
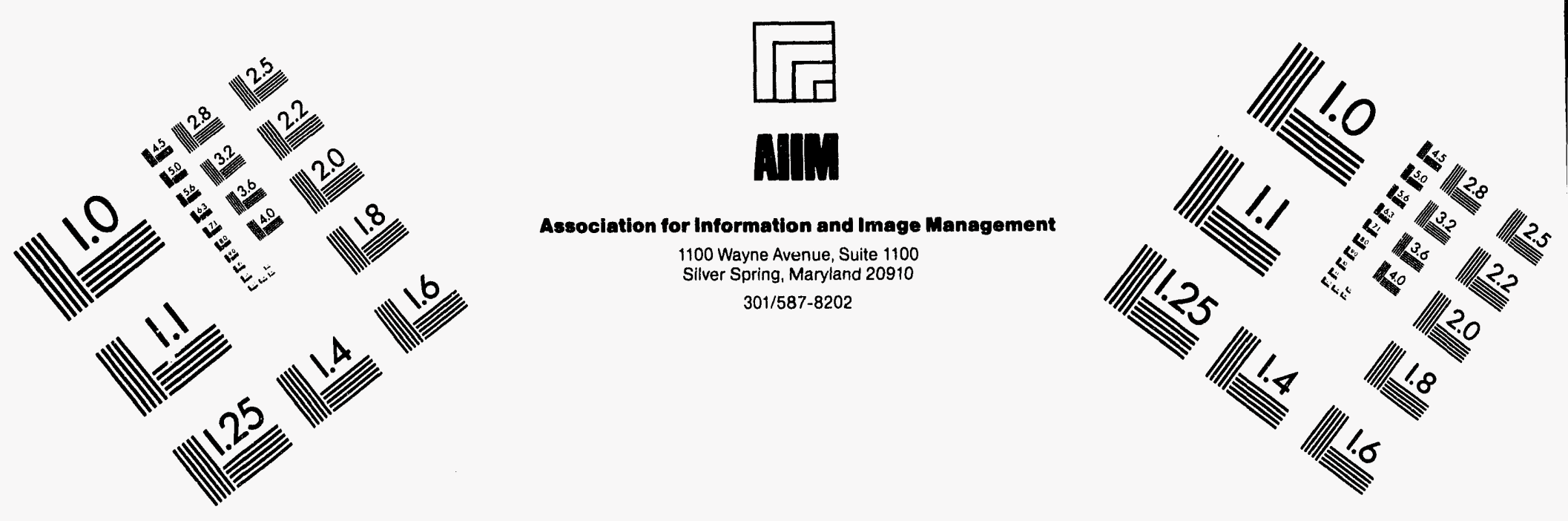

Centimeter

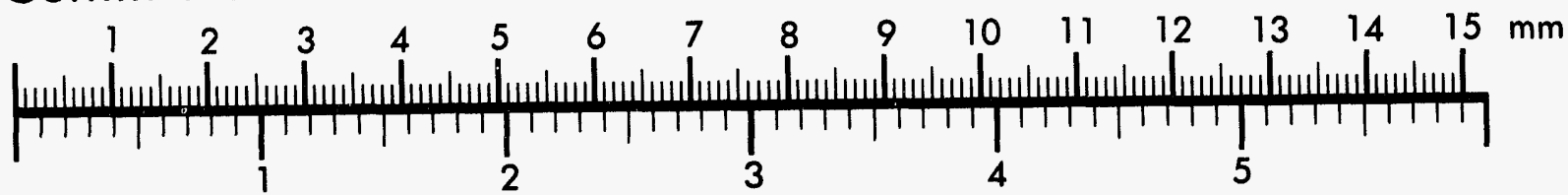
Inches
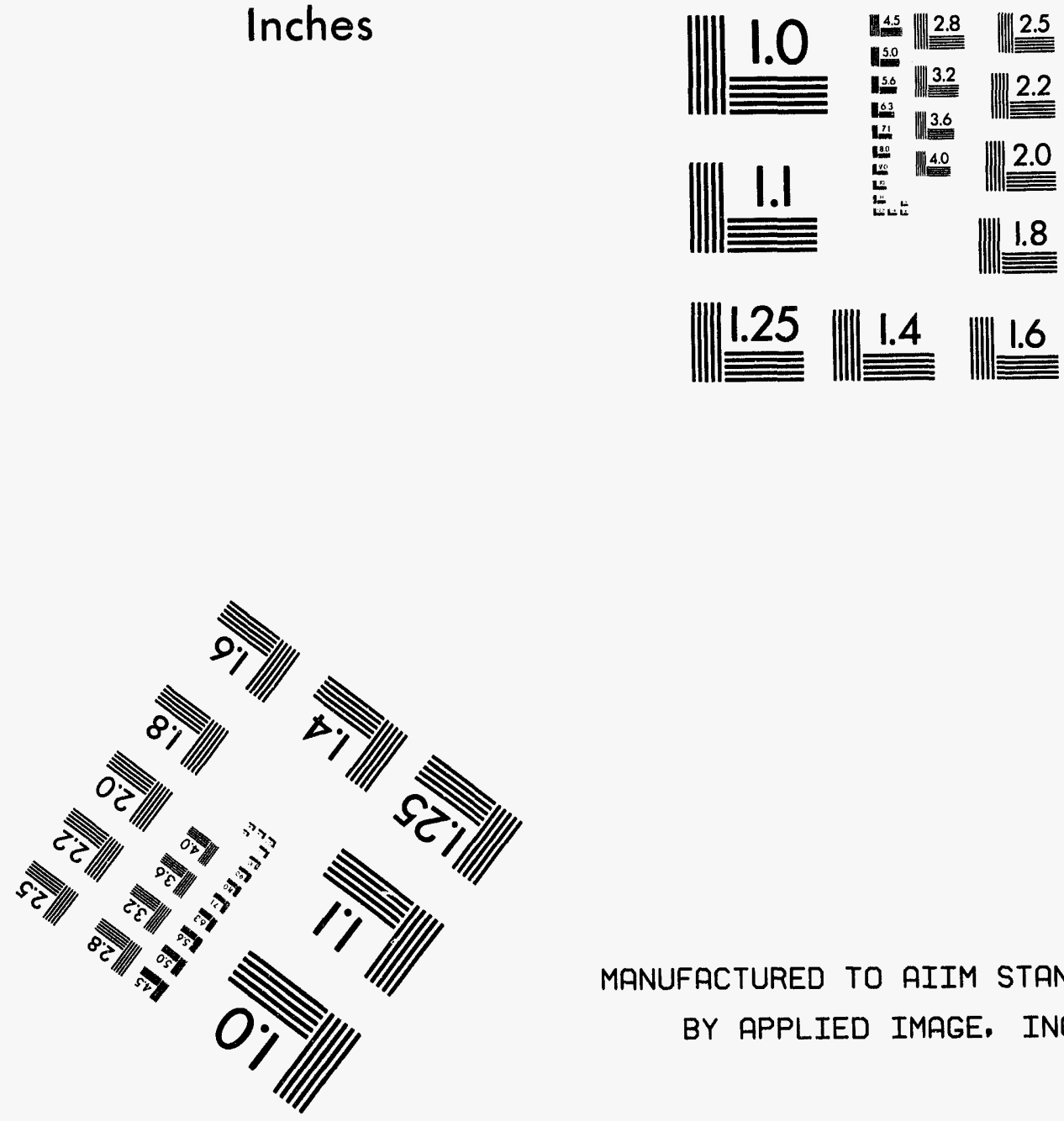

MANUFACTURED TO AIIM STANDARDS

BY APPLIED IMAGE, INC.

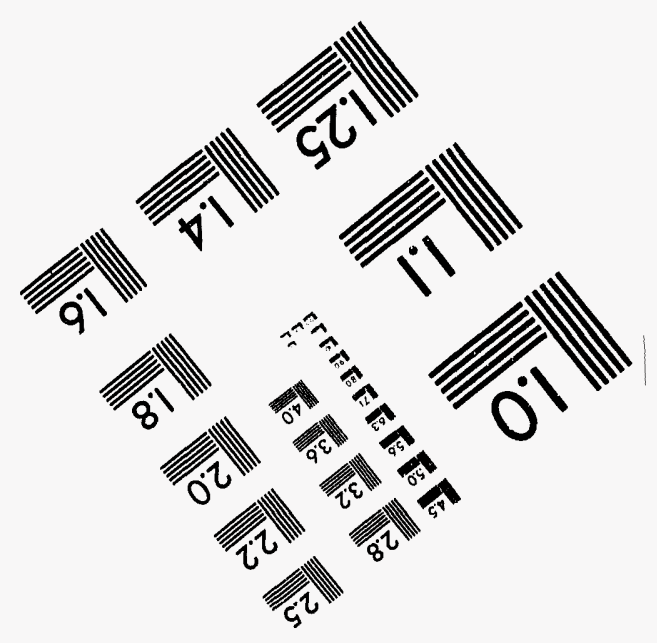



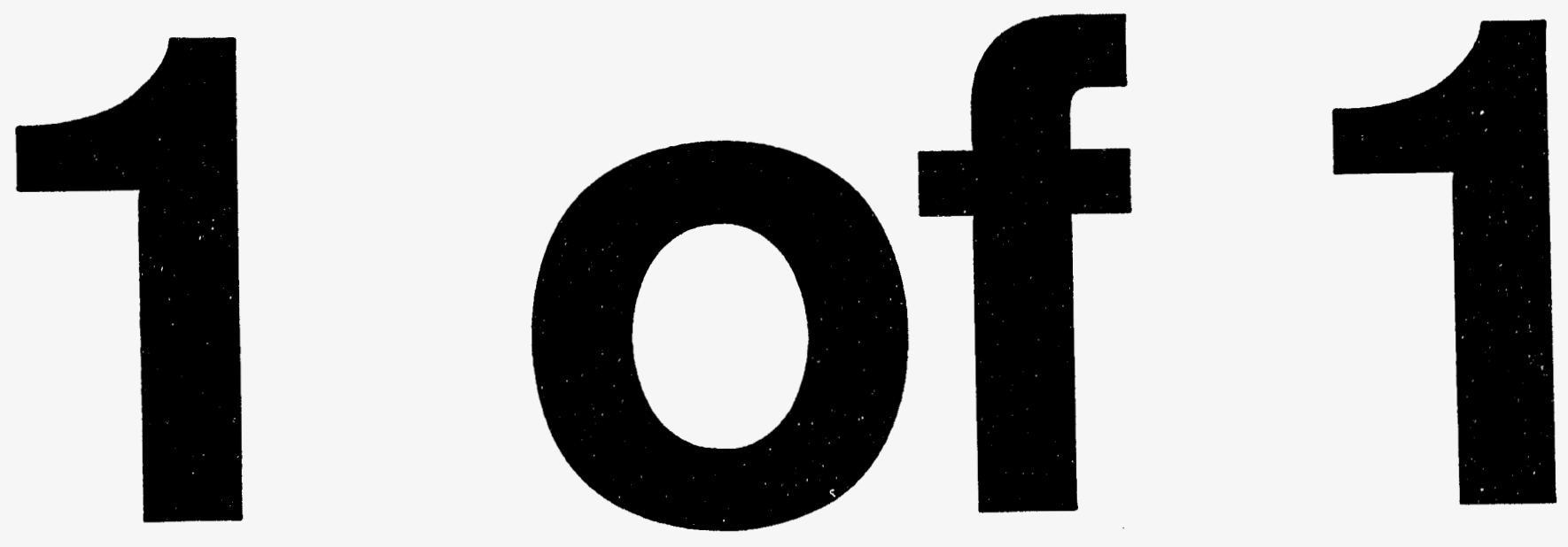


\section{Instrumentation and Controls Division \\ GENERAL INFORMATION FOR OPERATION OF THE HIGH-TEMPERATURE ELECTROMAGNETIC CONTAINERLESS VACUUM INDUCTION FURNACE}

C. A. Hahs

R. J. Fox

Date Published-June 1994

Prepared for the

George C. Marshall Space Flight Center National Aeronautics and Space Administration George C. Marshall Space Flight Center, Alabama, under Interagency Agreement DOE 1281-A126

Prepared by

OAK RIDGE NATIONAL LABORATORY

Oak Ridge, Tennessee 37831-6285

managed by

MARTIN MARIETTA ENERGY SYSTEMS, INC.

for the

U.S. DEPARTMENT OF ENERGY

under contract DE-AC05-84OR21400

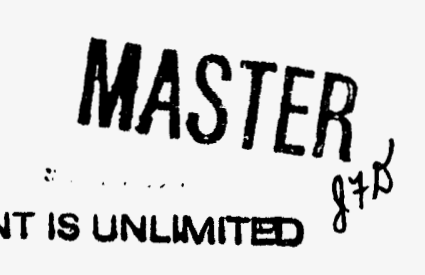




\begin{abstract}
The High-Temperature Electromagnetic Containerless Vacuum Induction Furnace was developed at Oak Ridge National Laboratory for the National Aeronautics and Space Administration (NASA), Marshall Space Flight Center, Alabama. The high-efficiency radio-frequency system developed for the conceptual design of the Modular Electromagnetic Levitator was created to evaluate this hardware on the KC135 microgravity airplane operated by NASA. Near-future KC135 flights are being planned to levitate, melt, and undercool 5-mm samples of niobium. General information on the operation of this hardware is included.
\end{abstract}




\section{GENERAL INFORMATION FOR OPERATION OF THE HIGH-TEMPERATURE ELECTROMAGNETIC CONTAINERLESS VACUUM INDUCTION FURNACE}

The laboratory equipment developed to position and melt niobium in microgravity at $-2500^{\circ} \mathrm{C}$ is a stand-alone system when installed within the $\mathrm{KC} 135$ microgravity airplane. The science requirements for the Modular Electromagnetic Levitator (MEL) dictated most of the design criteria for the $\mathrm{KC135}$ High-Temperature Electromagnetic Containerless Vacuum Induction Furnace. The science requirement stipulated that the MEL should provide a vacuum in the $10^{-9}$-torr $\left(1.33 \times 10^{-7} \mathrm{~Pa}\right)$ range. Although laboratory tests have demonstrated that the vacuum system proposed for the MEL can be achieved, maintaining this vacuum level will require bake-out auxiliary equipment that will not be installed on the $\mathrm{KCl} 135$ hardware. The vacuum system designed for the $\mathrm{KC} 135$ vacuum furnace will produce vacuum levels of $10^{-8}$-torr $\left(1.33 \times 10^{-6} \mathrm{~Pa}\right)$; after the sample-positioning actuator was installed, the best vacuum attainable was in the $10^{-7}$-torr $\left(1.33 \times 10^{-5} \mathrm{~Pa}\right)$ range. This range is adequate to melt niobium during $\mathrm{KC1} 35$ flights. Even though the sample-positioning actuator is bellows sealed, small gas passages increase the pumping time required to obtain pressures in the $10^{-8}$-torr $\left(10^{-6} . \mathrm{Pa}\right)$ range.

The vacuum system consists of a mechanical vane pump, provided with a switch that automatically turns it off during the few seconds of microgravity to prevent oil loss from the pump; a zeolite molecular sieve; and two 3.5-L/s turbornolecular pumps. One of the turbomolecular pumps is connected to the vacuum chamber, and the second turbomolecular pump is used as a backing pump for the first pump. The mechanical vane pump, the turbomolecular pumps, and the heater for the zeolite molecular sieve operate from the 115-Vac power supply from the aircraft.

The radio-frequency (rf) power system developed for this furnace operates from the 28-Vdc power bus of the KC135 aircraft. The efficiency of the if generator and heater coil system is $-36 \%$ when $5-\mathrm{mm}$ niobium spheres are being processed. Both the generators and the of coils used in the $\mathrm{KC} 135$ flight hardware were developed for the MEL to accomnodate the limited 28-Vdc power budget available from the shuttle. The left- and right-hand-wound coils are referred to as livitation coils when used for ground base work since the lower coil supports the sample. These coils are referred to as positioning coils when used in microgravity since the left- and right-hand-wound coils provide forces that center the sample in the cusp field. The levitation (cusp) and heating coils for dual-frequency power generators are shown in Fig. 1. In microgravity, the leftand right-hand-wound coils provide the (magnetic) B-field that forces the sample to the center of the coil assembly. The two 2-turn right- and left-hand-wound coil (levitation coils), illustrated in Fig. 1, are adequate for mis rogravity experiments; however, three left and three right turns perform better in laboratory experiments. During discussions regarding microgravity experiments, these coils are referred to as positioning coils since they position the sample within the center of the cusp field (Fig. 2). The levitation (cusp) 


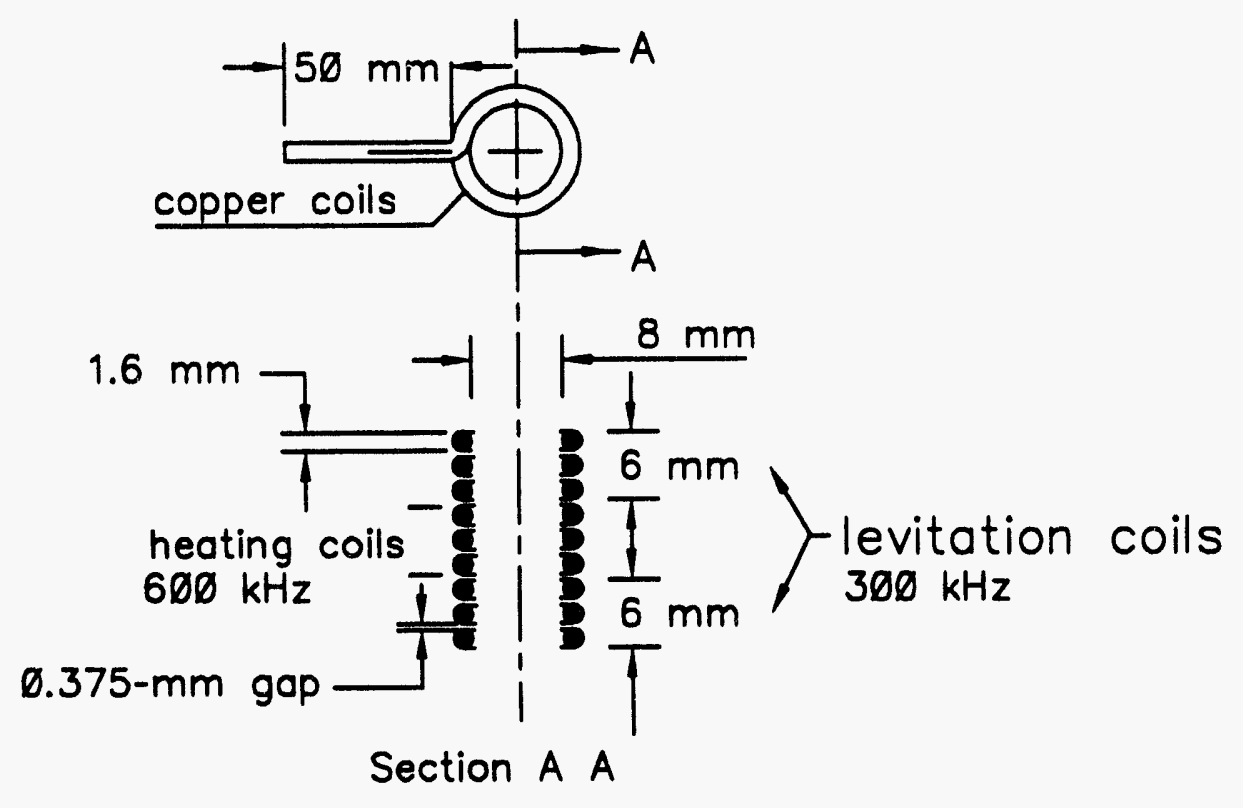

Fig. 1. Levitation (cusp) and heating coils for dual-frequency power generators.

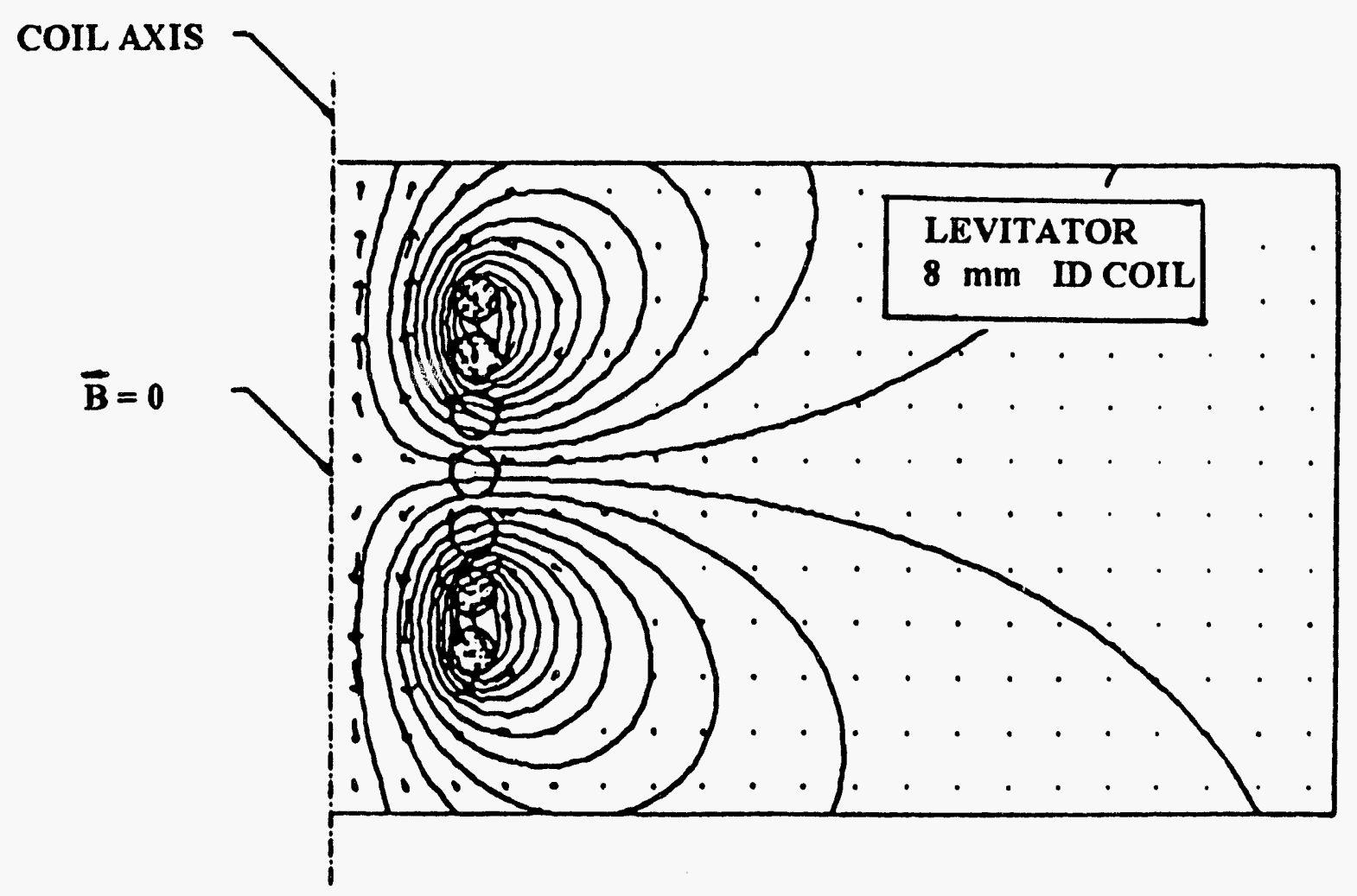

Fig. 2. "Cusp" coil B-field map. 
coils operate from a generator producing rf current at $-300 \mathrm{kHz}$. The 3-turn of heating coil shown in Fig. 1 operates from a second generator that provides current at $-600 \mathrm{kHz}$ to the heating coils. A dual-power control panel (Fig. 3) is provided to select the level of power provided to the coils. During the development of the hardware to meet the requirements for the MEL, a $2.5-\mathrm{kW}$ laboratory generator was used to demonstrate that niobium could indeed be levitated, melted, and undercooled at $1 \mathrm{~g}$. Samples of gold, lead, silver, niobium, Inconel, and aluminum were positioned between the cusp coils during $\mathrm{KCl} 135$ flights to demonstrate that $<50 \mathrm{~W}$ of power was required to adequately position niobium within the center of the cusp field. Since previous KC135 flights were used to demonstrate that the vacuum system hardware could survive the $\mathrm{g}$ loads imposed upon it during microgravity flights, a second flight was made to demonstrate that samples levitated by the cusp coil were stable when the ferrite damper magnets were in place. A final test is required to demonstarte that niobium samples can be melted and undercooled during the $20 \mathrm{~s}$ of microgravity available on the KC135 aircraft.

While the furnace is operating, heat must be removed from the if electronic components and from the if coils by circulating water through the coils. The heat radiated from the hot sample to the if coils is also removed by coolant passing through the coils. The schematic of the cooling system is shown in Fig. 4. The heat exchanger used to remove heat from the coolant is an automotive heater which provides a fan to force air across a single-stage radiator. Water (25\% triethylene glycol) is pumped through the system by a small gear pump that provides $-12 \mathrm{~mL} / \mathrm{s}$ at $60 \mathrm{psig}\left(4.5 \times 10^{5} \mathrm{~Pa}\right.$, gauge). It is extremely important that all air be removed from the cooling system during operation of the furnace in microgravity. Air is removed from the gear pump to prevent the gear pump from losing prime and to prevent air from entering the if coils. All air must be removed from the coolant before the furnace is operated in the laboratory or in the KC135. Just a small bubble of air may cause the if coils to fail while the sample is processed. All air is normally removed from the cooling system in the laboratory by using an air aspirator. The aspirator pulls a vacuum on the coolant system prior to backfilling with coolant.

An air-filled bellows inside the bubble trap expands and contracts to compensate for coolant volume changes as the coolant temperatures change. The fluid entrance and exit ports in the bubble trap are arranged to produce a centrifugal spin in the coolant to drive small air bubbles to the center of the trap and prevent them from being discharged to the pump. Air collected in the spin field is visible in the center of the top plate of the trap (at $1 \mathrm{~g}$ ) and can be vented from the system by loosening the Teflon fitting at the top of the bellows stem. All air must be removed at $1 \mathrm{~g}$ before the system is loaded on the KC135.

A video camera is mounted rigidly to the top of the table and is used to record experiments. Two pairs of headphones are provided for communication and to record voices of the investigators. Data and significant events will be recorded on the tape during experiments. The vidio cassette recorder component of the camera is used to study data collected during each flight, so it is imperative to record specific information 

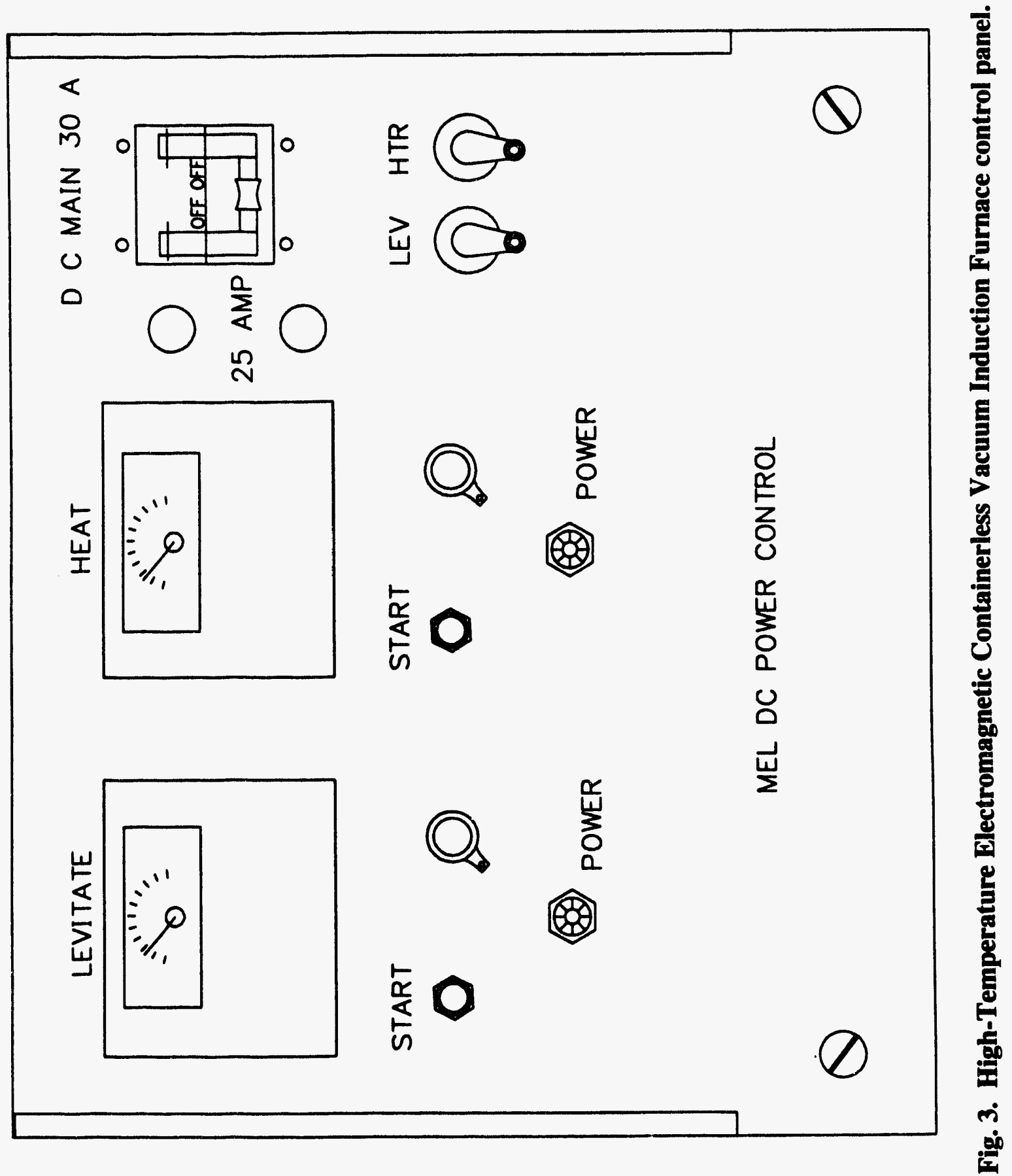


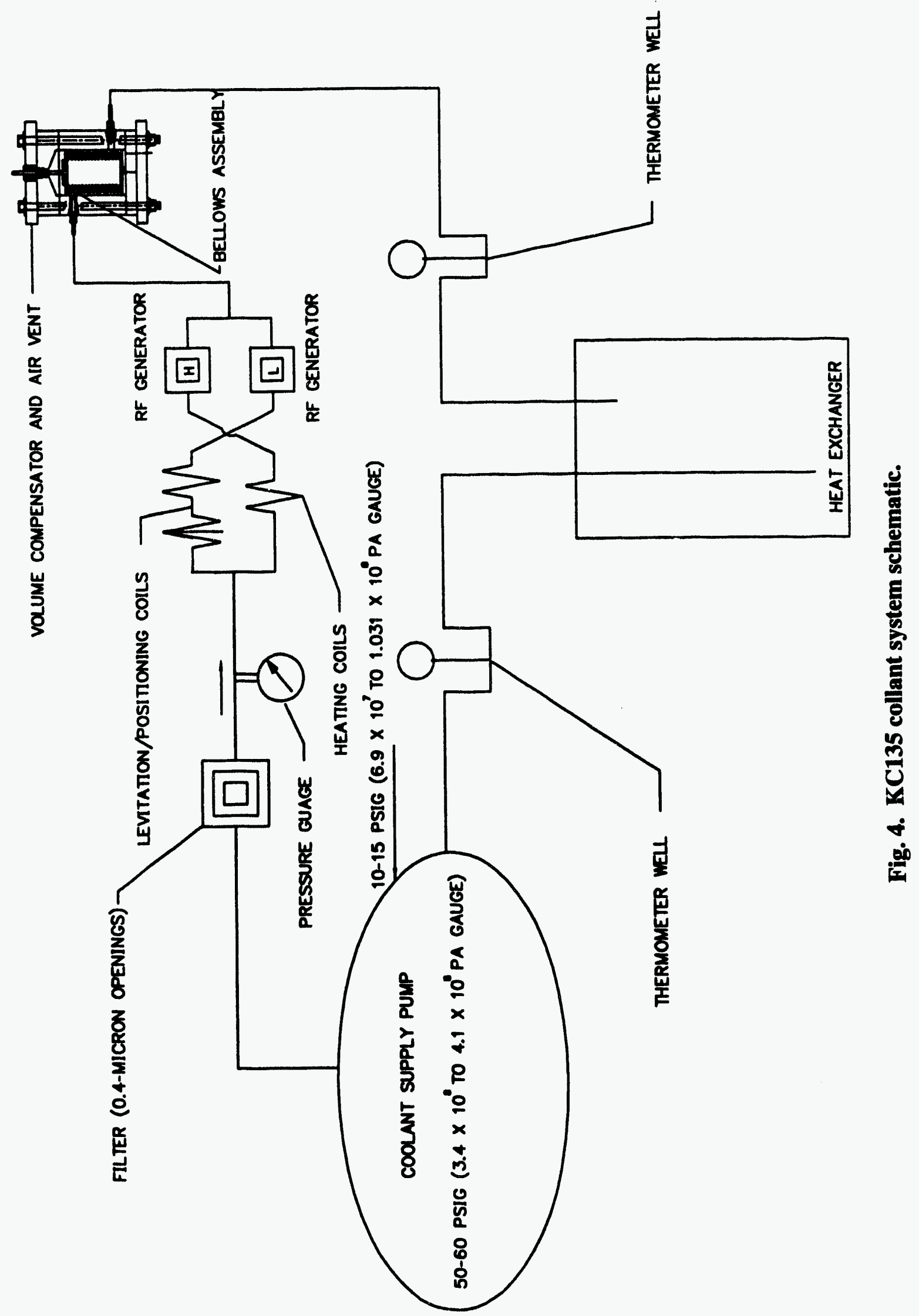


on the video tape. The camera has a frame rate of $60 / \mathrm{s}$; however, shutter speeds range from $1 / 100$ to $1 / 10,000$ per second. Shutter speeds should be recorded on the audio part of the tape since they are not recorded on the video tape. The camera incorporates a computer-controlled iris that will reduce the aperture small enough to allow viewing of the molten niobium sample without additional optical filters even if the manual overide is on. Unfortunately, since the iris is computer controlled, sometimes the camera shuts down automatically at critical times. Operators should work with hot samples at $1 \mathrm{~g}$ to learn how to adjust the camera shutter and iris during experiments. The camera should remain in the record mode most of the time to prevent shutdown.

Although researchers can use the camera color monitor to observe experiments, direct vision is also provided for the operator via an optical path, which is more convenient when samples are being positioned in the levitation coil. When viewing hot samples, the operator must use filters for eye protection. It has been found useful to have goggles that provide a filter for one eye and clear glass for the other eye. This provision will allow the operator to see the sample when it is either cold or hot. The samplehandling mechanism is used to position the sample in the coils during experiments. It is important for operators to learn how to manipulate the sample on the post to minimize the probability of imposing spin to the sample. This is very important during 1-g experiments; however, spin should not cause a problem during microgravity flights. A manipulator reference scale is provided on the outside of the vacuum chamber to aid the operator in visualizing where the sample is with respect to the heating and positioning coils.

The dual-power control panel (Fig. 3) provides operators the means to regulate power supplied to the heating and positioning coils. Meters that monitor the dc current to both the heating and positioning coils provide very good reference points to help the operator perform experiments within the few seconds available during microgravity flights.

The Tektronics TDS-420 scope attached to the end of the worktable is provided to record sample temperatures and to record the recalescence at the top and bottom of the sample. The mounting structure for the pyrometer and light meters for doing this experiment has been fabricated, but the electronic components associated with the light meters and the pyrometer have not been completed. The solidification velocity of niobium was included in the science requirements for the MEL.

All electrical power for this equipment is supplied from the ac and dc buses of the $\mathrm{KC} 135$. It is important to check out the power supply for the 28-Vdc and 115-Vac systems to ensure that active circuits will furnish adequate power to the system. The 28-Vdc bus should furnish $-30 \mathrm{~A}$ to the power line connectors located behind the power control box. The aircraft bus voltage should be within $28 \pm 2$ Vdc. The 115-Vac bus voltage should be within $115 \pm 4$ Vac.

The coolant provided to remove heat from rf coils and the electronic switches is a closed-loop system (Fig. 4). Pump discharge pressure is displayed on a gauge at the 
pump exit line. Normally, the pump will discharge coolant at $60 \mathrm{psig}\left(4.14 \times 10^{5} \mathrm{~Pa}\right.$, gauge) to the coils and switches in the power control box. Pressure drop across dirty filters will cause the discharge pressure to drop. If this pressure drops below 50 psig $\left(3.45 \times 10^{5} \mathrm{~Pa}\right)$, the filter should be replaced. The filter can be changed by removing the stainless steel nut which provides access to the filter. With a new filter in place, the pump should deliver $60 \mathrm{psig}\left(4.14 \times 10^{5} \mathrm{~Pa}\right)$. The adjusting screw on the end of the pump may be turned clockwise to increase the pressure slightly. Note: if the filter is removed, the entire coolant system must be evacuated again and made free of air bubbles.

\section{POWER CONTROL SYSTEM}

The High-Temperature Electromagnetic Containerless Induction Vacuum Furnace power control system provides the operator the means to adjust the power level to the if positioning and heating coils. Its magnetic circuit breaker also controls all dc power to the water pump, heat exchanger fan, and rf system. Power from the $115-\mathrm{Vac}$ receptacles is supplied to the vessel light, turbomolecular pumps, vacuum vane pump, Tektronics TDS-420 scope, video camera, zeolite trap heater, ion gauge, Hastings gauge, and all other computers or hardware that operate from these receptacles.

The two ammeters on the panel respond to changes in the dc power supplied to the heating and positioning coils. As current is increased in the positioning coils, a sample on the post starts heating up even at the midpoint of the windings. Sample heating is increased as the sample is moved either up or down into the positioning coils. Since this system is designed for 10-mg operation, microgravity flights are absolutely necessary to establish experiment procedures. The equipment should be operated at $1 \mathrm{~g}$ so operators can become familiar with its operation.

For the first microgravity flights, it is advisable to provide a small tungsten wire (guard wire) above the positioning coils to prevent the sample from leaving the confinement of the rf coils. As mentioned above, samples of gold, lead, silver, niobium, Inconel, and aluminum were held in the positioning coils by using only $4 \mathrm{~A}$ from the 28-Vdc bus. During these first tests, it was observed that microgravity time varied from 15 to $26 \mathrm{~s}$. With this observation in mind, investigators may want to plan to heat niobium samples on the post to near $2000^{\circ} \mathrm{C}$ before entering microgravity. (Laboratory tests have been made to ensure that the post will not be damaged even at these high temperatures.) This procedure will allow more time in microgravity to melt the sample by using the heating coil. By heating the sample just before the aircraft reaches microgravity, more time will be allowed to melt and undercool the sample. For the first few KC135 flights, operators should practice positioning samples without using the heating coils to gain confidence in operation of the system. Forces imposed on samples during microgravity parabolas by motion ( $g$-jitter) of the airplane were sufficient to force gold samples out of the cusp field provided by the sample-positioning coils. At the time a gold sample was lost, only $4 \mathrm{~A}$ were used to position the sample in the if field. The power level may be increased to the positioning coils to help heat the sample during pull-up. With this increase in power level, the sample-positioning force will be adequate to overcome the g-jitter and hold the sample near the center of the heating coil. 
Only microgravity flights can be used to establish the most desirable procedures. It is very important to use microgravity for undercooling experiments, but it must be done very carefully because there is a great deal of risk in melting samples at $1 \mathrm{~g}$. If the sample escapes the coils, it will end the experiment for the flight. Replacement of the sample will require that the top of the vessel be removed, and the system must be pumped down for at least $20 \mathrm{~min}$ before samples can be processed. When the post is in position at the bottom of the coil assembly, samples can excape the cusp field by only the top coil. A tungsten wire across the top of the coils will provide total containment of the sample and prevent the loss of the sample. This wire will be in the line of sight with the sample; however, since the wire is small, it should not present a serious problem to operators. The wire may be desirable for the first flights until operators have more confidence in containment of the sample by using the rf field.

\section{COAXIAL CURRENT TRANSFORMER}

The $\mathrm{rf}$ power to the heating and positioning coils is supplied by a water-cooled toroidal ferrite-core current transformer (Fig. 5). Power into the transformer is via link coupling. The single-turn secondary winding is just the coaxial shell itself, which connects to the low-loss coaxial feedthrough into the vacuum vessel. The use of the coaxial design was necessary to reduce rf heating losses in the transformer mounting flange assembly.

\section{POWER INVERTER}

A pair of water-cooled, 60-A metal-oxide-semiconductor field-effect transistor (MOSFET) power switches in a push-pull class D circuit (Fig. 6) is link coupled to the resonant transformer. Self-excitation avoids any operation off-resonance that might result from load changes. The inverter operates at parallel resonance for maximum efficiency, and switching is done at the voltage zero voltage crossing.

\section{SCHEMATIC DIAGRAM OF THE If SYSTEM}

The design of this system is unique. A thorough understanding of MOSFET switches is required for maintaining this system. The diagram of the electronic and electrical circuit (Fig. 7) is provided to aid technicians in maintenance of this system.

\section{BASIC OPERATING PROCEDURES}

1. Verify proper connection of the ac and dc power to the aircraft power supply.

2. Turn on the MAIN power magnetic breaker.

3. Verify that the sample is in the proper position on the post.

4. Turn on the the circuit you want to activate the heater (HTR) or levitator (LEV) (positioner).

5. Check to see that the power controllers are set to zero.

6. Push the appropriate START button momentarily for the heater or positioner circuit, and observe the red light to confirm power to the system. 
7. While turning the appropriate power controller clockwise, observe the dc ammeter power settings. If the sample does not warm up at $5 \mathrm{~A}$, turn the system off and restart from step 2.

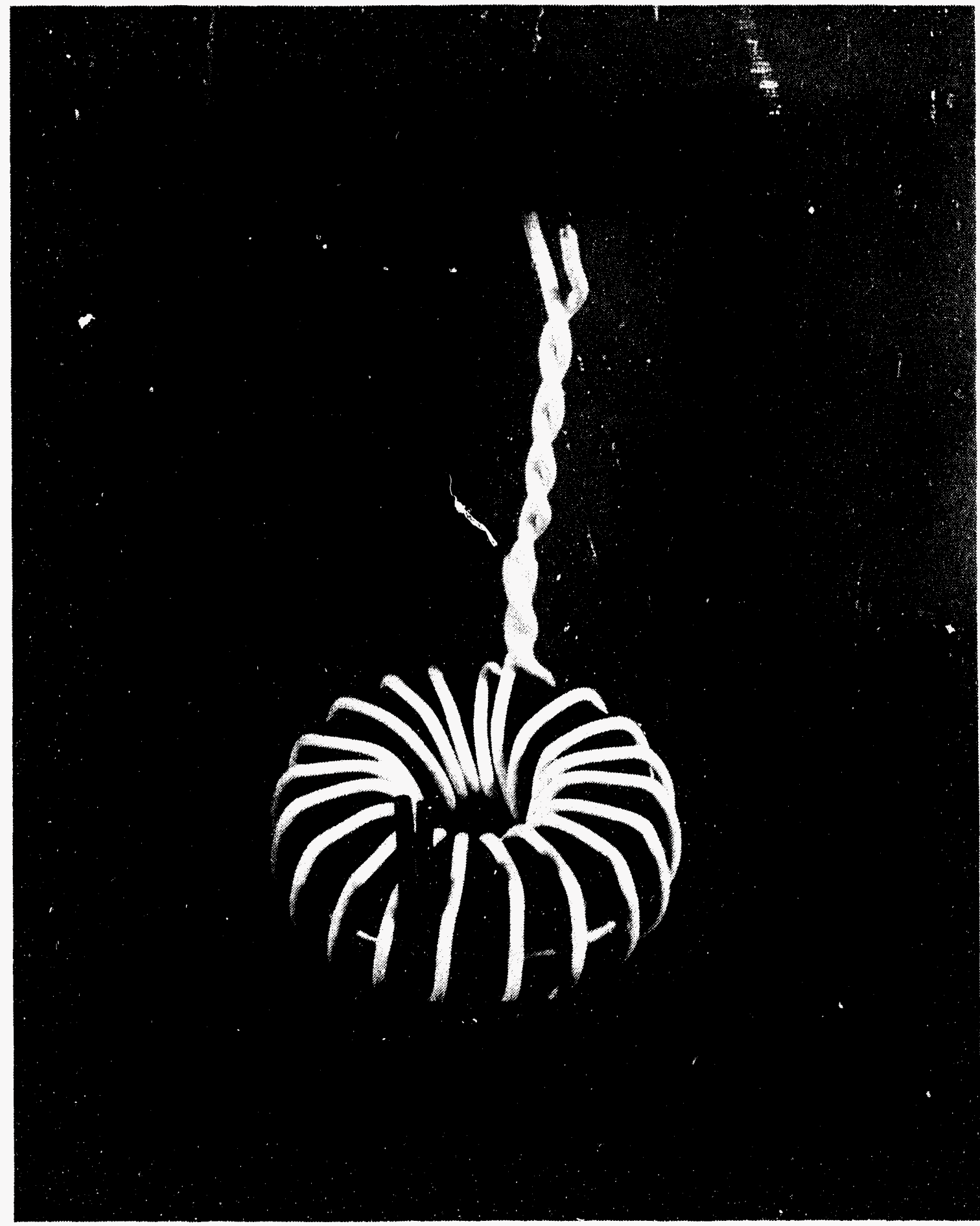

Fig. 5. Primary winding on water-cooled toroidal ferrite-core current transformer. 


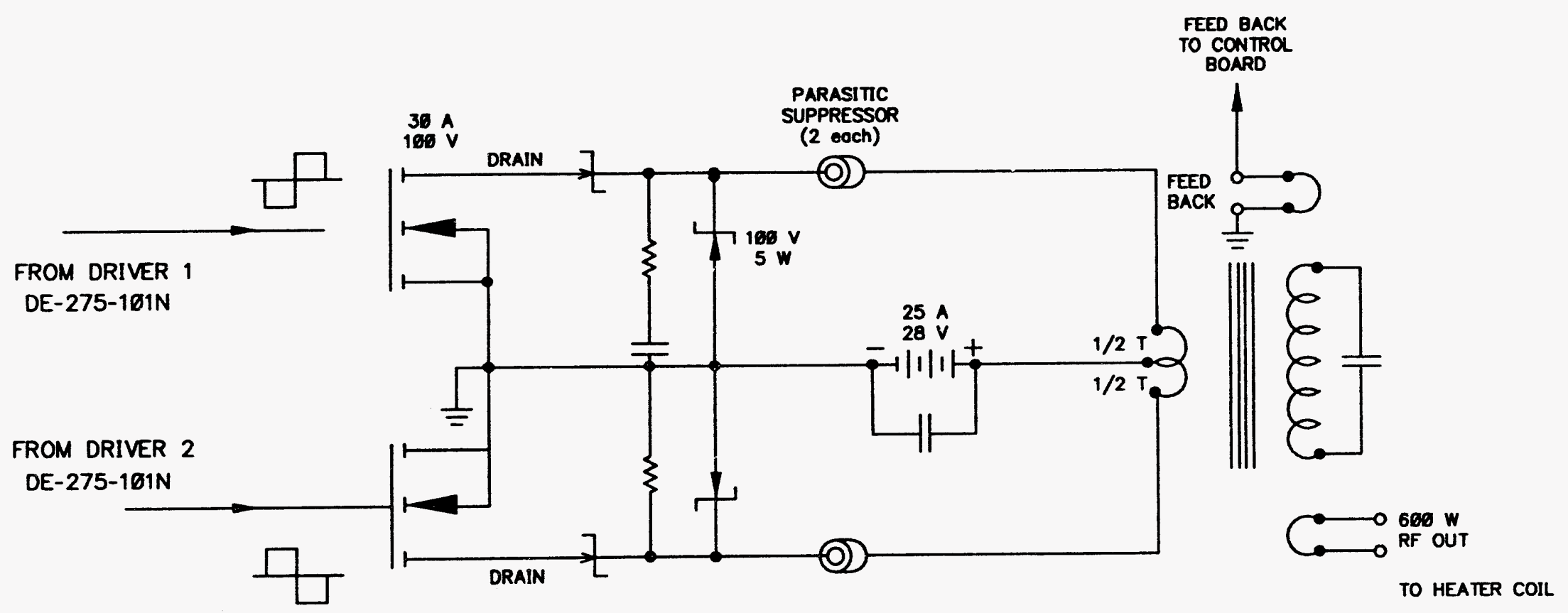

Fig. 6. Power output stage, push-pull MOSFET switches. 


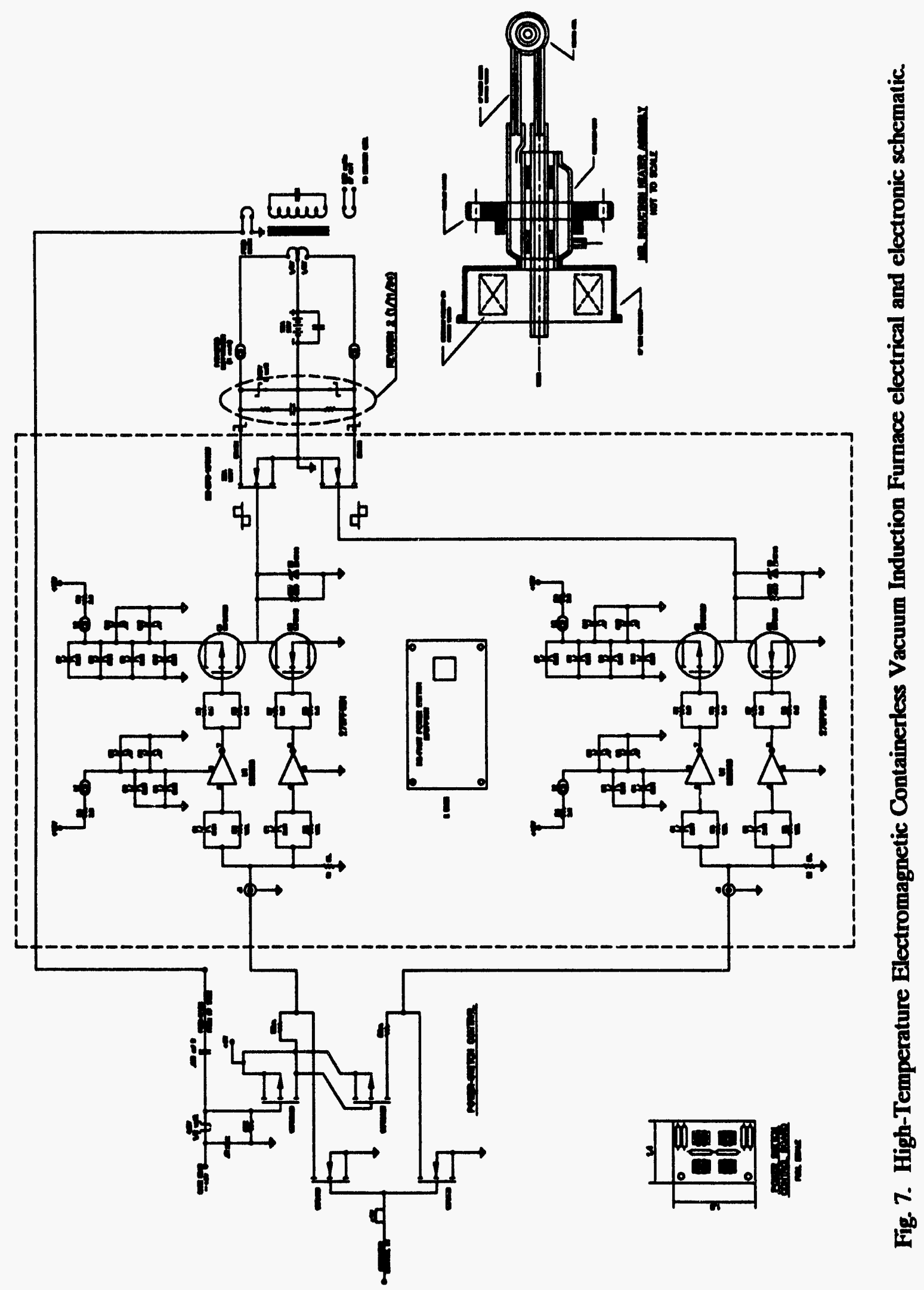


ORNLM-3595

\section{INTERNAL DISTRIBUTION}

1-2. C. A. Hahs

3-4. R. J. Fox

5. H. R. Brashear

6. B. G. Eads

7. D. N. Fry

8. D. W. McDonald

9. D. R. Miller

10. G. N. Miller

11. R. E. Uhrig

12. R. L. Shepard
13. J. O. Stiegler

14. G. W. Allin

15. J. A. Williams

16. D. F. Craig

17-18. Central Research Library

19. Y-12 Technical Reference Section

20-21. Laboratory Records

22. Laboratory Records-Record Copy

23. ORNL Patent Section

24. I\&C Division Publications Office

\section{EXTERNAL DISTRIBUTION}

25. Clark Darty FA25, Building 4302, George C. Marshall Space Flight Center, Marshall Space Flight Center, AL 35812

26. Buddy V. Guynes FA25, Building 4302, George C. Marshall Space Flight Center, Marshall Space Flight Center, AL 35812

27. Michael B. Robinson ES75, George C. Marshall Space Flight Center, Marshall Space Flight Center, AL 35812

28. Dinah B. Higgins LA20, Building 4201, George C. Marshall Space Flight Center, Marshall Space Flight Center, AI 35812

29. B. Chexal, Electric Power Research Institute, 3412 Hillview Avenue, Palo Alto, CA 94303

30. V. Radeka, Brookhaven National Laboratory, Instrumentation Division, 535-B, Upton, NY 11973

31. M. M. Sevik, Carderock Division, Naval Surface Warfare Center, Code 1900 , Bethesda, MD 20084-5000

32. R. M. Taylor, Leeds and Northup, Sunneytown Pike, North Wales, PA 19454

33. Assistant Manager for Energy Research and Development, DOE-ORO, P.O. Box 2001, Oak Ridge, TN $37831-8600$

34-35. Office of Scientific and Technical Information, U.S. Department of Energy, P.O. Box 62, Oak Ridge, TN 37831 

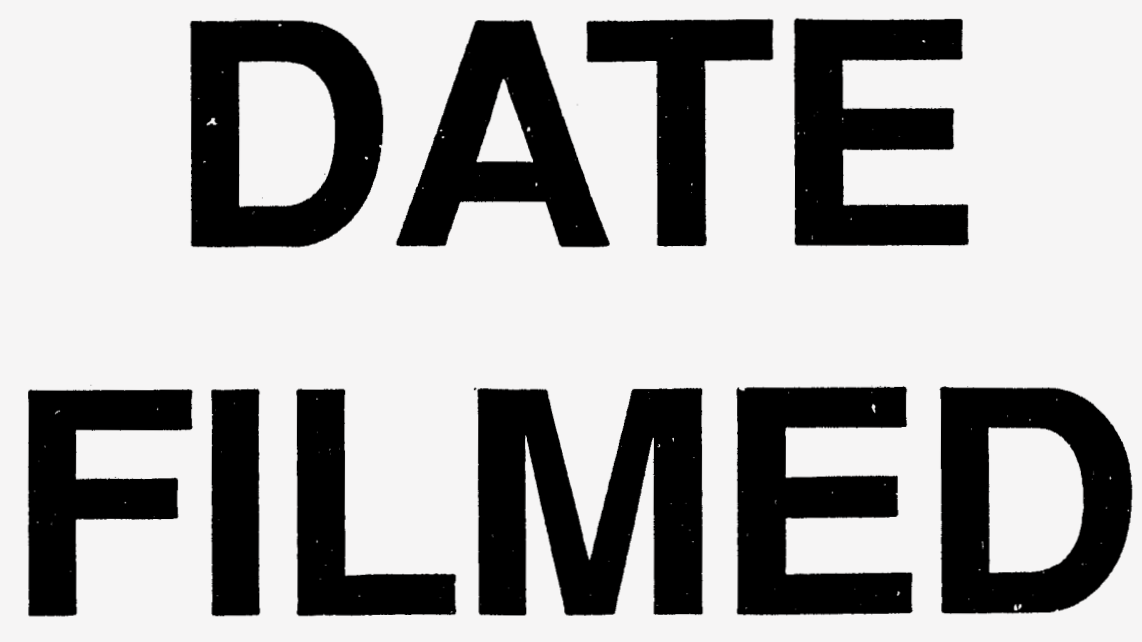

$9 / 20 / 94$
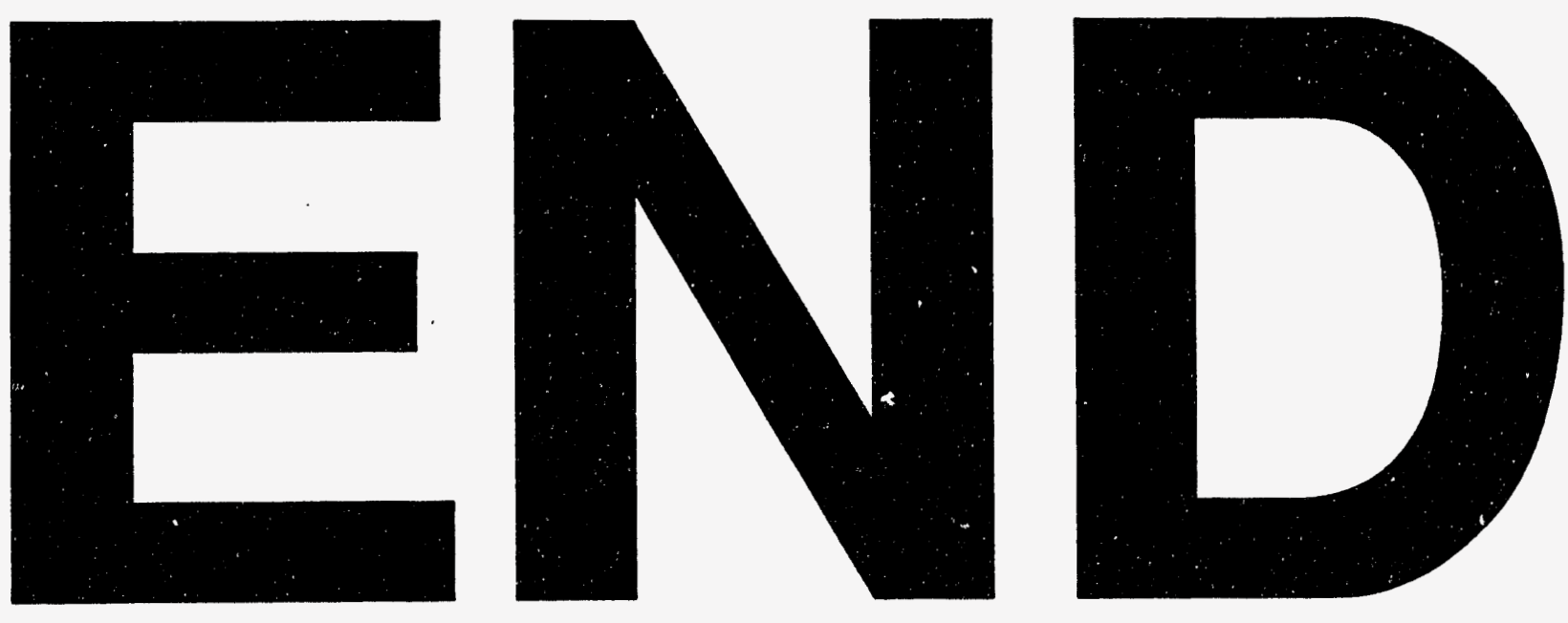
